rev.relac.int.estrateg.segur.9(1):37-56,2014

\title{
LA NECESIDAD DE ENTENDERSE: INTERDEPENDENCIA Y COMPETENCIA EN LAS RELACIONES HISPANO-MARROQUÍES*
}

\author{
Antonio Palomar Ruiz-Gálvez ${ }^{* *}$
}

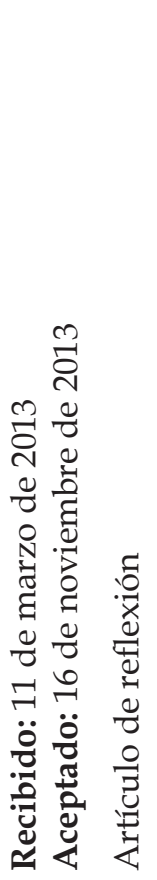

\section{RESUMEN}

El objetivo de este artículo es analizar el grado de amenaza que puede suponer Marruecos para España como consecuencia, principalmente, de sus reclamaciones territoriales sobre las posesiones españolas en el norte de África. En él se aprecia que Marruecos ha desarrollado diversas formas de presionar a España para intentar obligarla a negociar sobre esos territorios. Sus métodos consisten en afectar los intereses nacionales españoles, para afectar a España a nivel interno, pero también están dirigidos a conseguir la atención de la comunidad internacional para socavar la posición española. A su vez, Madrid ha desarrollado una estrategia encaminada a confrontar el desafío marroquí. Esa estrategia se basa en la disuasión y en el fomento de la interdependencia económica. No obstante, se observa que, pese a los esfuerzos españoles

* Este trabajo es el producto de una investigación realizada en el marco de la línea de investigación de «seguridad internacional» del doble grado en Relaciones Internacionales y Traducción e Interpretación de la Universidad Pontificia de Comillas. No se ha recibido ayuda financiera para su elaboración.

** Internacionalista, traductor e intérprete. Universidad Pontificia de Comillas. Madrid, España. antoniopalomarruizgalvez@gmail.com 
REVISTA DE RELACIONES INTERNACIONALES, ESTRATEGIA Y SEGURIDAD

y a los crecientes lazos socioeconómicos entre ambos Estados, la presión continuada de Marruecos puede dar lugar a situaciones de verdadera tensión, como la de la crisis de Perejil.

Palabras clave: España, Marruecos, conflicto, competencia, amenaza, estrategia.

\title{
NEED FOR UNDERSTANDING: INTERDEPENDENCE AND COMPETITION IN THE SPANISH- MOROCCAN RELATIONS
}

\begin{abstract}
The purpose of this paper is to analyze the actual threat that Morocco poses to Spain, particularly as a result of its territorial claims on Spanish possessions in North Africa. The paper shows that Morocco has developed a number of ways to pressure Spain in order to force it to negotiate the sovereignty of those territories. Moroccan methods aim at harming Spanish national interests, thus affecting Spain internally, but they also mean to attract the attention of the international community to undermine the Spanish position. Madrid, In turn, has developed a strategy designed to face the Moroccan challenge. This strategy is based on both deterrence and economic interdependency. Nevertheless, it is observed that, in spite of Spanish efforts and the growing socioeconomic ties between both countries, the continuous pressure of Morocco may well lead to situations of actual threat, as in the Perejil crisis.
\end{abstract}

Keywords: Spain, Morocco, conflict, competence, threat, strategy

\section{A NECESSIDADE DE ENTENDER-SE: INTERDEPENDÊNCIA E COMPETIÇÃO NAS RELAÇÕES HISPANO- MARROQUINAS}

\section{RESUMO}

O objetivo deste trabalho é analisar o grau de ameaça que representa o Marrocos para a Espanha em consequência, principalmente, das suas reivindicações territoriais sobre as possessões espanholas ao norte da África. Nele aborda-se que o Marrocos vem desenvolvendo várias formas de pressão para tentar forçar a Espanha a negociar sobre esses territórios. Seus métodos consistem em afetar os interesses nacionais espanhóis para afetar a Espanha internamente e adicionalmente estão dirigidos a chamar a atenção da comunidade internacional para minar a posição espanhola. Por sua vez, Madrid desenvolveu uma estratégia apontada a enfrentar o desafio marroquino. Esta estratégia baseia-se na dissuasão e promoção do fomento da interdependência econômica. No entanto, parece que, apesar do esforço espanhol e os crescentes laços sócio-econômicos entre ambos os Estados, a pressão do Marrocos continua e pode levar a situações de tensão real, como a crise do Perejil.

Palavras-chave: Espanha, Marrocos, conflito, competição, ameaças, estratégia. 


\section{INTRODUCCIÓN}

Marruecos es, sin duda alguna, uno de los principales ejes de la política exterior española. No es para menos. Además de por una simple cuestión de vecindad y proximidad, España no puede permitirse ignorar a un país que, pese a todas sus carencias y a su debilidad comparativa, se ha convertido en un aliado preferente de Estados Unidos, en un país con vocación de potencia regional, con fuerte influencia en el Magreb, con estrechos lazos con el otro gran vecino de España, Francia, y en un socio preferencial de la Unión Europea. Por todo ello, es natural que España fomente el progreso de las relaciones bilaterales con su vecino alauita. Y, sin embargo, que en las relaciones entre España y Marruecos existen tensiones es un hecho tan innegable como poco sorprendente. Incluso cuando las relaciones bilaterales entre ambos parecen atravesar su mejor momento, estas tensiones, generalmente latentes, amenazan con tomar el protagonismo de las relaciones hispano-marroquíes y con hacer estallar un conflicto diplomático. Así, aunque en los últimos años se ha avanzado muchísimo en varias materias importantes a nivel bilateral -como en cooperación o en relaciones económicas y comerciales-, hay una serie de elementos estructurales que introducen una "conflictividad cíclica" (del Miño, 2005:132) que marca, en última instancia, la relación diplomática entre ambos reinos.

Esos elementos estructurales que provocan tensiones entre los dos Estados tienen su origen, como analizaremos en este trabajo, en multitud de factores. Uno de ellos, por ejemplo, es el de la tremenda desigualdad que caracteriza las relaciones entre los dos países, separados por tan solo unos pocos kilómetros de estrecho. Al fin y al cabo, según el Índice de Desarrollo Humano de Naciones Unidas, el Estrecho de Gibraltar constituye la frontera más desigual de la Unión Europea, ya que, mientras que España se sitúa en el puesto 23 del IDH, Marruecos no aparece hasta el puesto 130 (ONU, 2012:1). Es indudable que esta desigualdad genera dinámicas complicadas tanto a nivel social como político, lo que favorece la aparición de tensiones entre España y Marruecos. En este trabajo se analiza el nivel de amenaza que suponen esas tensiones.

\section{EL CONFLICTO TERRITORIAL, PRINCIPAL FOCO DE TENSIÓN}

Sin ninguna duda, las posesiones africanas de España son una de las principales fuentes de conflicto con Marruecos. Varios son los territorios en disputa. Los principales son las ciudades autónomas de Ceuta y Melilla, y, en menor medida, el archipiélago de las Islas Canarias. Sin embargo, España también posee en el norte de África una serie de territorios conocidos tradicionalmente como plazas de soberanía. Entre estas plazas de soberanía se encuentran el Peñón de Vélez de la Gomera, las Islas Chafarinas y las Islas Alhucemas. Además, en los últimos tiempos también se han incluido en la categoría de plazas de soberanía la Isla de Alborán, que, sin embargo, forma parte del término municipal de Almería desde el siglo XIX, y la Isla de Perejil, pese a que históricamente ha sido un peñón deshabitado y una suerte de "tierra de nadie". 
Marruecos considera que estos territorios son los últimos vestigios del Protectorado español en Marruecos (1912-1956). Por ello, exige la retirada total de la presencia española de las plazas de soberanía. Esta tesis coincide con la de los grupos de presión marroquíes con mayor carácter irredentista y nacionalista, que aspiran a conseguir una expansión que dé lugar a lo que se conoce como Gran Marruecos. Por el contrario, España arguye que los citados territorios son inequívocamente españoles, ya que forman parte de España desde hace siglos, con independencia del periodo del Protectorado (Sueiro, 2003).

La controversia acerca de la soberanía territorial entre los dos reinos viene de antiguo, y sus bases se asientan, particularmente en el caso español, sobre argumentos históricos con siglos de antigüedad. Por ejemplo, las razones españolas para justificar la soberanía de Madrid sobre el norte de África han llegado incluso a citar la idea de que, ya desde tiempos de Roma, en el siglo III d.C., el norte del actual Marruecos formaba parte de la provincia de la Hispania romana como la subdivisión conocida como Mauritania-Tingitania (García Figueras, 1939). Igualmente, la historiografía española usa como argumento el que, incluso tras la caída de Roma, el norte de África siguiera relativamente bajo el dominio de los nuevos gobernantes de Hispania: los visigodos. Posteriormente, la Corona de Castilla, que se consideraba a sí misma heredera del reino visigodo, justificó sus ambiciones territoriales en el continente vecino con el pasado visigodo del norte de África.

Las islas Canarias han estado bajo dominio español desde finales del siglo XIV; Melilla, desde 1497; Alborán, desde 1540; Alhucemas, desde 1560; Vélez de la Gomera, desde 1564, y Ceuta, desde 1580. Tras más de cuatro siglos de presencia continuada en estos territorios, la soberanía española sobre ellos está, en general, totalmente aceptada por la comunidad internacional. Otro factor importante es que, mientras que Marruecos reclama las plazas de soberanía con el argumento del colonialismo, España nunca ha considerado sus posesiones norteafricanas actuales como colonias, ni siquiera en tiempos del Protectorado, y tampoco son vistas como colonias a nivel internacional, lo que resta fuerza a los argumentos marroquíes, que intentan vincular las plazas de soberanía con Gibraltar, que sí es considerada como colonia por la ONU, al contrario que Ceuta, Melilla y los demás territorios españoles ${ }^{1}$ (ONU, 2013).

\section{LOS INTERESES DE AMBOS PAÍSES EN LOS TERRITORIOS EN DISPUTA}

Una vez vistas las razones históricas por las que cada país reclama para sí los territorios en disputa, es necesario estudiar los intereses subyacentes ligados a estos territorios. Y es que tanto España como Marruecos tienen depositados importantes intereses en Ceuta, Melilla, las Islas Canarias y las demás plazas españolas en África.

1. En la lista de las Naciones Unidas de territorios no autónomos a descolonizar solo aparece una colonia en África: el Sáhara Occidental. 
Una de las principales claves de la relevancia de las plazas de soberanía es el factor demográfico. Así, Ceuta y Melilla presentan una densidad demográfica de 4.313 y 6.023 habitantes por kilómetro cuadrado, respectivamente, lo que supone el dato más alto de las autonomías españolas, mientras que la densidad de población en las Canarias es de 279 habitantes por kilómetro cuadrado (INE, 2012). En total, estos tres territorios reúnen una población total de unos 2.220.000 de personas, es decir, alrededor del 5,3\% de la población española total. Es obvio, pues, que España no puede permitirse renunciar a territorios que albergan a un porcentaje tan alto, en términos relativos, de su población. Asimismo, no hay que olvidar que la población de estos territorios es, en su mayor parte, de cultura y origen españoles, por lo que el coste político y de prestigio internacional para España derivado de la pérdida esos territorios sería aún mayor ${ }^{2}$. Por otra parte, el factor demográfico y poblacional está vinculado también a la producción de riqueza de estos territorios. Si bien las posesiones españolas en África no son, ni mucho menos, las más ricas del país, su contribución al PIB nacional no es desdeñable. Según el Instituto Nacional de Estadística, dicha aportación ascendió en 2010 a los 43.000 millones de euros, mientras que el Producto Interior Bruto total de España es de alrededor de un billón de euros. Es más, uno de esos territorios, el archipiélago canario, es uno de los principales destinos turísticos de España: según datos del INE y del Instituto Canario de Estadística, de los cerca de 56 millones de turistas extranjeros que visitaron España en 2011, más de 10 millones lo hicieron en Canarias (INE, 2012, y ISTAC, 2012). Teniendo en cuenta la importancia del turismo para la economía española, se puede apreciar el valor que tienen las Canarias como generador de ingresos.

El impacto demográfico, no obstante, debe analizarse también desde la perspectiva del interés marroquí. En efecto, la demografía de Ceuta y Melilla, en rápida variación en los últimos tiempos, es precisamente uno de los pilares de la reivindicación de Marruecos sobre ambas ciudades autónomas, además de un factor de presión para España. Así, mientras que en 1970 la población europeo-cristiana de origen español constituía el 90\% de los habitantes de Ceuta y de Melilla, en la actualidad ese porcentaje ha bajado a tan solo el 55\%. El descenso se debe a la entrada masiva de migrantes árabes y bereberes musulmanes procedentes, en la inmensa mayoría de los casos, de Marruecos. Esa población de origen marroquí asciende ya al $41 \%$ de la población, lo que la convierte en una minoría muy significativa que, además, se mantiene muy unida en sus lazos religiosos y étnicos de origen marroquí (Navarro del Rey, 2001). Este hecho ha servido a Marruecos para consolidar su argumento de que la presencia española en la zona es de carácter colonial, dominadora de una población, en origen, bereber y norteafricana, no

2. Es evidente que no es lo mismo perder una colonia con la que la metrópoli apenas comparte lazos de ningún tipo que perder una parte integrante de su territorio poblada por sus propios nacionales. No hay más que ver, por ejemplo, el trauma nacional que supuso para Francia perder Argelia, oficialmente un departamento francés más y con una población de franceses muy superior a la de otros territorios de ultramar cuya pérdida apenas se dejó sentir, como en el caso del propio Marruecos. Huelga decir, por supuesto, que Ceuta y Melilla son infinitamente más españolas que francesa fue Argelia. 
europea. Sin embargo, es necesario un apunte al respecto: en ambas ciudades, la mayor parte de la población bereber, aunque ha conservado sus raíces religiosas y culturales, se ha integrado admirablemente en la población española, y los movimientos irredentistas promarroquíes que hay en ella no son de momento dominantes (Pérez, 2013).

Aparte de la cantidad de población de estos territorios, de su demografía étnica, religiosa y cultural y de la riqueza bruta que generan -factores que ya de por sí los convierten en valiosos y deseados-, cabe destacar el tema de los recursos naturales presentes en ellos o en sus inmediaciones. A este respecto, mientras que Ceuta, Melilla y las demás plazas de soberanía al norte de Marruecos apenas poseen recursos naturales propios como consecuencia de su reducida extensión, las Islas Canarias, una vez más, cobran especial relevancia debido a que en ellas o en sus proximidades existen recursos naturales de gran atractivo comercial. En concreto, hay dos elementos que podrían potenciar al archipiélago como lugar de explotación de recursos y aumentar el valor estratégico de las islas para España:

- El primero es la pesca. La flota pesquera española es la mayor de la Unión Europea en términos de tonelaje y de capturas, y a nivel mundial ocupa el tercer puesto detrás de la japonesa y de la noruega (Eurostat, 2012). Por ello, que cerca de las Islas Canarias existan caladeros de pesca ricos es de gran importancia para España. De hecho, el puerto pesquero de Las Palmas es el tercero de todo el país en orden de relevancia, y en las islas abundan las industrias conservadoras y congeladoras. Sin embargo, en los últimos tiempos los beneficios de la pesca en la zona han disminuido, debido, precisamente, a la ocupación marroquí del Sáhara Occidental en 1975 y a la tensión existente entre España y Marruecos en la zona a raíz del conflicto territorial, que ha provocado que las flotas españolas cada vez pesquen menos en las aguas cercanas a la antigua colonia del Sáhara Occidental (a las que se accede desde los puertos canarios), a pesar de que los caladeros de la zona han sido tradicionalmente de los más importantes para la flota pesquera española. Por otro lado, Marruecos ha contribuido de manera activa y consciente al declive de la industria pesquera española en esas aguas mediante el bloqueo de las negociaciones sobre pesca con la Unión Europea (GEVIC, 2012).

- El segundo recurso natural que puede hacer aumentar el interés de España y de Marruecos en el archipiélago canario, además de incrementar su valor productivo, es el petróleo. En 2012 se confirmaron las intenciones de REPSOL de realizar prospecciones en el archipiélago canario para comprobar la existencia de una gran bolsa de petróleo en la zona. Se estima que dicha bolsa de petróleo, cuya presencia parece casi segura según todos los expertos, alberga un total de mil millones de barriles de crudo, lo que equivale a 144.000 barriles al día durante veinte años al ritmo de explotación estándar, es decir, más del 13\% del consumo total de España (INE, 2012). España es un país con un consumo de petróleo muy alto (1,45 millones de barriles al día, cifra mayor que las de Francia e Italia), pero tremendamente dependiente del abastecimiento exterior, ya que su producción petrolífera apenas cubre el $0,2 \%$ de su demanda. La existencia de petróleo en las proximidades del archipiélago, por lo tanto, supone un incremento del valor estratégico de las islas y de 
la relevancia para España de llevar a cabo una política firme de defensa de su soberanía sobre las mismas y sobre sus aguas territoriales. Este punto es fundamental, porque la bolsa de petróleo se ha descubierto en aguas cuya soberanía está en disputa desde hace décadas entre ambos países, como consecuencia de la desidia de los distintos gobiernos españoles, que después de tantos años siguen sin fijar claramente los límites de las aguas canarias $^{3}$. Por otro lado, la teoría general del Derecho Internacional es que las aguas de la zona económica exclusiva se extienden hasta las 200 millas náuticas de la costa, pero en esa distancia coinciden los derechos españoles y los marroquíes. Estableciendo una línea mediana equidistante entre ambos reinos, los yacimientos se encuentran en el lado español, pero Marruecos no acepta esa división, y de hecho en los últimos tiempos ha concedido licencias de pesca y explotación más allá de ese límite (Montero, 2012). De esta manera, el descubrimiento de petróleo en las islas ha agravado el conflicto territorial con Marruecos y, a menos que el Gobierno español se muestre firme en la defensa de los intereses españoles, hará que se establezca un precedente de negociación que provocará, a su vez, que Marruecos tenga una causa para decir que las Canarias son territorios en disputa, en lugar de inequívocamente españoles.

Finalmente, al analizar la importancia de los territorios españoles en África, hay que mencionar el altísimo valor estratégico de los enclaves españoles en la zona. La importancia estratégica de las posesiones españoles reside en su situación geográfica. Para empezar, los puertos de Ceuta y de Melilla son los más importantes de los de la costa sur del Estrecho: por un lado, el puerto de Tánger, muy considerable, está orientado hacia el oeste, hacia el Atlántico, y, por otro, Marruecos solo dispone de un puerto mediterráneo de similares características en la zona, el de Alhucemas ${ }^{4}$, más pequeño que los anteriores (Marquina, 2008). Ceuta, situada en una península de difícil acceso y fácil defensa, cuenta con un buen puerto y se considera, junto con Gibraltar, una de las llaves del Estrecho. Melilla, aunque menos protegida y de más complicada defensa, forma parte también del conocido eje Baleares-Estrecho-Canarias, la principal zona de despliegue y de acción de las Fuerzas Armadas españolas (Bartumeus, 2004). El Estrecho de Gibraltar es una de las rutas marítimas más importantes del mundo; por él pasan anualmente más de cien mil buques, entre mercantes y navíos militares. La importancia de controlar un paso tan crucial mediante la posesión de enclaves en ambas orillas del mismo parece, por tanto, evidente. Ceuta y Melilla constituyen además un excelente puente para España, así como una magnífica plataforma militar y diplomática para extender su influencia en el norte de África.

3. La salida de España del Sáhara Occidental en los años setenta provocó que las Canarias se convirtieran, súbitamente, en un territorio fronterizo cuyas aguas había que delimitar según las leyes internacionales. La Constitución (artículos 132.2 y 149.1) estipula que corresponde a las autoridades nacionales delimitar las aguas jurisdiccionales marítimas, pero los sucesivos Gobiernos han prestado poca atención a esta responsabilidad. Así, por ejemplo, se da la paradoja de que, al no estar bien definidas las aguas españolas, ir en barco desde Tenerife hasta Gran Canaria supone cruzar aguas internacionales, en lugar de aguas interiores.

4. Aun así, Marruecos está construyendo una base naval en Alcazarseguer para reforzar su presencia en el Estrecho. 
Algo parecido sucede en el caso de las Canarias. Desde hace siglos, el cabotaje por la costa occidental africana es una de las rutas más importantes para el tráfico comercial, y las Canarias, desde su descubrimiento, forman parte indiscutiblemente de ella, al ser la conexión tradicional de Europa, África y América. Debido a sus buenas infraestructuras (el puerto de Las Palmas es el tercero con más actividad de España y el mejor acondicionado de la zona de África occidental), a su pertenencia al mercado común europeo y a los vientos alisios -que favorecen la navegación hacia América del Sur-, entre otros factores, el archipiélago es un punto de recalada ineludible para los buques mercantes en ruta hacia el Atlántico sur, lo que lo convierte en un emplazamiento estratégico muy importante. En 2011 pasaron por él más de 9.000 embarcaciones comerciales, y gestionó veinte millones de toneladas en mercancías (Puertos de Las Palmas, 2013).

En definitiva, los territorios reclamados por Marruecos significan para España el control, en dos tramos clave, de las dos rutas comerciales que circunnavegan África, ya sea por el norte -vía estrecho de Gibraltar-, o por el sur -vía Canarias-, lo que muestra el valor estratégica de las posesiones españolas (Ballesteros, 2013).

\section{LA ESTRATEGIA MARROQUÍ}

Ya se ha visto en el apartado anterior que hay muchos factores dentro de los territorios españoles disputados por Marruecos que son fundamentales para los intereses nacionales de ambos Estados. Al beneficio económico y al control de posiciones de altísimo valor geoestratégico, hay que añadir, desde el punto de vista marroquí, el enorme impulso que el éxito en su estrategia de presión para obtener Ceuta, Melilla y las Canarias supondría para las aspiraciones del reino alauí de convertirse en la potencia regional dominante del Magreb, un objetivo nacional desde hace décadas. No obstante, esa estrategia de presión se ha construido desde muchas vertientes, aunque todas ellas comparten la misma intención: debilitar a España y su posición internacional y promover el abandono español de los territorios reclamados por Marruecos. Las principales líneas de actuación en esta estrategia son la permisividad con la migración ilegal y el fomento de la misma; el bloqueo casi sistemático de las negociaciones con la Unión Europea sobre acuerdos de pesca; el apoyo institucional público a organizaciones que piden la anexión de Ceuta y Melilla y, finalmente, el apoyo tácito a grupos ilegales y mafias cuya fuente de financiación principal es el tráfico de drogas de Marruecos a España.

La permisividad con la migración ilegal, sobre todo en las áreas de Ceuta y de Melilla, es una de las principales bazas en la baraja de presión de Rabat. Aunque en ocasiones el Gobierno marroquí se muestra colaborativo, cuando lo estima oportuno abre la puerta a las pateras que parten desde el Sáhara hacia las Canarias y permite que se produzcan asaltos organizados a las vallas de protección de Ceuta y Melilla. Marruecos utiliza esta táctica para obtener concesiones políticas de España, como una menor presión en el asunto del Sáhara Occidental, pero la migración ilegal de marroquíes a las plazas españolas, sobre todo a las de Ceuta y Melilla, 
es muy beneficiosa para Marruecos por otras razones. En primer lugar, gracias a la migración Marruecos ha conseguido alterar en gran medida la demografía de las ciudades autónomas, con el interés de hacer a la población local más proclive al cambio de soberanía. Así, alrededor del $42 \%$ de los habitantes de Ceuta y de Melilla profesa la religión musulmana y mantiene lazos culturales, familiares y, en definitiva, identitarios con Marruecos, y se estima que su crecimiento es tres veces más rápido que el de la población de origen español, mientras que en 1986 los musulmanes no llegaban a conformar el 21\% de la población (Planet, 2000).

En segundo lugar, mediante la inmigración ilegal, Marruecos logra dañar la imagen exterior de España, ya que su actuación transmite una gran sensación de inseguridad en la frontera. Así, a pesar de que el impacto real de la migración marroquí en el conjunto de España es más bien pequeño, cada vez que se produce un incidente relacionado con este tema, todos los noticiarios españoles abren con la noticia, y muchos medios internacionales critican el uso de las famosas vallas de Ceuta y Melilla, protegidas en algunas secciones con alambre de espino y concertinas, para contener la inmigración ${ }^{5}$. Se alzan entonces las voces de numerosas organizaciones no gubernamentales que afirman que España vulnera los derechos humanos (Amnistía Internacional, 2006), lo que Marruecos utiliza para reforzar su argumento de que Ceuta y Melilla deberían pasar a su dominio, no solo por una cuestión de "justicia" -desde el punto de vista marroquí-, sino por una necesidad de seguridad que, según Rabat, España no es capaz de mantener en la zona. La muerte, a principios de 2014, de quince inmigrantes cuando trataban de entrar en Ceuta no beneficia en absoluto la postura española.

La segunda forma de presión en la estrategia marroquí es la del bloqueo sistemático de las negociaciones con la UE en materia de pesca. Ya se ha visto que España es el país de la Unión con mayor flota pesquera, y también es, sin duda, el que más intereses nacionales tiene en esta actividad. Asimismo, se ha mencionado el hecho de que uno de los caladeros tradicionales y más rentables de los pesqueros españoles ha sido el situado en las aguas al oeste del Sáhara Occidental (Holgado y Ostos, 2002). De hecho, la flota española ha llegado a ser bastante dependiente de los caladeros de la zona, lo que proporciona a Marruecos un gran poder de presión (Lobina, 2013). De esta manera, desde que Marruecos administra la antigua colonia española, las condiciones de pesca en la zona no han dejado de empeorar, debido sobre todo a un esfuerzo consciente de las autoridades marroquíes por perjudicar a España ${ }^{6}$. A este respecto, el último acuerdo de pesca es bastante ilustrativo. En el acuerdo de 2007-2011, Marruecos exigió nada menos que 36,1 millones de euros anuales a cambio de su firma. Ese alto precio hacía que la UE solo recuperase el 83\% de su inversión (Lobina, 2013). Es decir, el acuerdo significaba pérdidas económicas para Europa, pero se firmó gracias a la presión de

5. La BBC, por ejemplo, llegó a comparar las vallas de las ciudades autónomas con el Muro de Berlín (Munáiz, 1)

6. Las condiciones han empeorado a pesar de que, legalmente, Marruecos no tiene derecho a negociar sobre esas aguas, ya que no le pertenecen, al ser el Sáhara Occidental un territorio ocupado que, según la comunidad internacional y las propias Naciones Unidas, debe ser descolonizado. 
la diplomacia española, pues España era el único país que se beneficiaba del tratado (España consiguió quedarse con 100 de las 119 licencias otorgadas). Sin embargo, al expirar el acuerdo en 2012, el Parlamento Europeo se negó a prorrogarlo, sin que España pudiera hacer nada, a menos que Marruecos redujera el precio exigido. Rabat, por supuesto, rechaza cualquier revisión de las condiciones (incluso pidió un aumento del precio), lo que ha dejado a miles de faeneros españoles sin trabajo.

El tercer pilar en el que Marruecos basa su estrategia de presión a España es el apoyo explícito del Estado marroquí a los movimientos irredentistas que reclaman la anexión de Ceuta y Melilla, además de las acciones del propio gobierno de Rabat para reafirmar sus "derechos históricos" sobre los territorios españoles. En efecto, en numerosas ocasiones los altos representantes de Marruecos han dejado patentes las intenciones de su país con respecto a Ceuta, Melilla y las demás plazas de soberanía españolas. El antiguo embajador marroquí en España, por ejemplo, llegó a decir en 2011 que "recuperar Ceuta y Melilla es un objetivo nacional" (Calvo, 2011:1). Asimismo, Marruecos proporciona un gran apoyo financiero, político y jurídico a las organizaciones que reclaman la cesión de los presidios españoles. La principal de estas organizaciones es el Comité de Liberación de Ceuta y Melilla. El líder de esta formación, nacido en Melilla, es Yahya Yahya, miembro del Senado de Marruecos y alcalde de Beni Ensar -localidad próxima a Melilla-, es decir, un representante del Estado marroquí. Él mismo declaró en 2012 que su organización cuenta con "mucho apoyo económico y respaldo del Gobierno islamista marroquí" (Téllez, 2012:1), además de con el "apoyo personal de Su Majestad Mohamed VI". Sus declaraciones no han sido desmentidas por las autoridades marroquíes, las cuales, por el contrario, hacen explícita su defensa de la causa en distintos foros internacionales, como en la Asamblea General de la ONU, donde el Gobierno de Marruecos reitera cada año que Ceuta y Melilla son ciudades marroquíes bajo ocupación española. También destaca el apoyo económico gubernamental a la asociación Coordinadora de la Sociedad Civil del Norte de Marruecos, que ha llegado incluso a amenazar con bloquear el comercio de pescado y de verdura con Melilla si cualquier líder nacional del Partido Popular vuelve a pisar la ciudad (Gutiérrez, 2010).

Si bien es consciente de que este tipo de iniciativas no van a tener como consecuencia la entrega de los territorios norteafricanos españoles, Marruecos realiza este considerable esfuerzo financiero y diplomático para mantener una presión constante sobre España y, especialmente, para conseguir que España reconozca la necesidad de comenzar una negociación sobre el estatus de los "territorios ocupados". Este es el principal obstáculo para la postura marroquí, pues España siempre se ha negado a cuestionar en lo más mínimo la españolidad de las ciudades autónomas y de las demás plazas de la zona. La comunidad internacional reconoce esos territorios como españoles, y la ONU no los incluye en su lista de colonias. Por ello, Marruecos intenta forzar a España a reconocer, aunque sea parcialmente, las reclamaciones históricas marroquíes, ya que sabe que, mientras no haya un debate político al respecto, la posibilidad de anexionar esos territorios es prácticamente inexistente, al menos por la vía diplomática. 
De esta forma, Marruecos trata de ablandar la postura española protestando en foros internacionales para llamar la atención mundial sobre el tema y haciendo que sea la "sociedad civil" marroquí la que lleve el peso de las protestas, para conseguir que España se vea obligada a reconocer que hay un problema social generado por su posesión de las plazas de soberanía africanas. Sin embargo, todos esos esfuerzos marroquíes son vanos mientras España se niegue a cuestionar su soberanía, aunque es cierto que el apoyo a la causa marroquí ha crecido en los últimos tiempos gracias a esas estrategias.

Finalmente, el cuarto y último elemento de la estrategia de presión marroquí es el del tráfico de drogas a España. El tráfico de drogas, sobre todo de cannabis y de hachís, es la principal actividad económica en la zona del Rif, el área del norte de Marruecos situada entre Ceuta y Melilla (Ruiz, 2003). Las superficies dedicadas al cultivo de la droga en el Rif aumentan cada $a_{n}{ }^{7}$. La Oficina de las Naciones Unidas contra la Droga y el Delito (ONUDD) estima que la gran mayoría del hachís incautado en Europa procede de Marruecos (ONUDD, 2012). Lo más preocupante es que, desde el inicio del reinado de Mohamed VI, la extensión de los cultivos de cannabis se ha extendido a un ritmo regular, al menos hasta 2003, fecha en que, según los últimos datos, el crecimiento se estancó. Es evidente tanto que Marruecos está al tanto de esta situación como que hace muy poco para erradicarla, hasta el punto de que su pasividad se puede interpretar como un apoyo tácito del tráfico de drogas - que siempre llegan a Europa a través de España, normalmente por Ceuta y Melilla-, un apoyo que tiene el doble objetivo de mantener el rentable negocio de la droga en sus regiones del norte, del cual el Gobierno también se beneficia, y de perjudicar a España, que es vista por sus socios europeos como un "coladero" de droga (San Martín, 2008:1).

El hecho de que Marruecos no tenga intención alguna de acabar con el tráfico de hachís se aprecia claramente en el resultado del plan que la Unión Europea puso en marcha ya en 1993 para reconvertir los cultivos de droga en el Rif en cultivos agrícolas rentables. A la vista de los datos actuales, queda claro que dicho plan fracasó estrepitosamente, debido al poco esfuerzo realizado por Rabat para poner fin a esta práctica (González, 2013). El tráfico de hachís -del que Marruecos es el principal productor mundial, según la ONUDD- de Marruecos a España supone un grave perjuicio para España, ya que provoca un deterioro continuado de su imagen internacional, además de tener un considerable impacto social que se traduce en un acceso más fácil de los jóvenes a la droga y, en última instancia, en un mayor gasto social por parte del Estado en materia de seguridad y en campañas de prevención y de desintoxicación (Echeverría, 2002).

7. En 1993, el Ministerio de Agricultura marroquí, bajo la apelación de «cultivos industriales», lo estimaba entre 65.000 y 74.000 hectáreas. Dos años más tarde, las cifras barajadas por el gabinete de estudios español INYPSA, que realizaba un estudio en la zona norte de Marruecos por cuenta de la UE, daban una superficie de 79.846 hectáreas. En el año 2000, el propio Ministerio de Agricultura marroquí daba ya la cifra de 90.000 hectáreas. Un año más tarde, en 2001, se superaban las 100.000 hectáreas dedicadas a este cultivo. 


\section{LA ESTRATEGIA ESPAÑOLA}

Una vez descrita la estrategia marroquí, es necesario centrarse ahora en la española. Si en el caso marroquí la anexión de las plazas de soberanía españolas para el país africano supondría un gran espaldarazo que, en el caso de España cualquier cesión, por mínima que fuera, en materia de soberanía implicaría un coste político y diplomático - por no hablar del económico - inmenso, tanto interna como externamente. Ningún gobierno español puede o está dispuesto a pagar ese precio. Sin embargo, en la disputa territorial con Marruecos, España, pese a su evidente ventaja en prácticamente todos los aspectos del mismo, se enfrenta a un importante inconveniente: como consecuencia, precisamente, de su ventaja, se encuentra en una situación en la que apenas tiene nada que ganar pero sí mucho que perder. Así, la respuesta española ante la estrategia de presión marroquí, descrita anteriormente, es básicamente defensiva. Pese a ello, España tiene que combinar al mismo tiempo esa respuesta defensiva con una actitud proactiva que le permita fomentar los intereses económicos españoles en Marruecos y mantener una buena relación con el país vecino sin ceder, no obstante, en lo tocante a la soberanía española de los territorios reclamados por Rabat. De esta manera, la estrategia española se basa en tres factores: contrarrestar, en la medida de lo posible, las armas utilizadas por Marruecos para forzar una negociación sobre Ceuta y Melilla; promover la interdependencia económica entre los dos países a través de acuerdos económicos e inversiones en el reino alauí; y, por último, impedir a Marruecos llevar la disputa territorial a cualquier ámbito que vaya más allá de lo estrictamente diplomático mediante la disuasión militar.

España ha diseñado distintas réplicas con las que responder a las estrategias de presión marroquíes. Aunque no todas ellas han tenido el mismo grado de éxito, han servido para amortiguar en gran medida el impacto de las tácticas marroquíes. Así, se ha procurado paliar el incremento de la migración magrebí y subsahariana procedente de Marruecos, provocada por la estudiada laxitud de las autoridades del país, con una mejora en las infraestructuras fronterizas españolas y con un aumento en el presupuesto dedicado al control de fronteras ${ }^{8}$. De esta forma, se ha reforzado el sistema de verjas gracias a la llamada sirga tridimensional, que tiene por objeto impedir la escalada de la valla, a pie o con la ayuda de escaleras, por parte de inmigrantes mediante la inclinación del vallado unos diez grados hacia el lado marroquí; y, a su vez, impedir también que los inmigrantes alcancen la segunda de las vallas gracias a un entramado de cables de acero trenzado. Asimismo, el nuevo dispositivo de seguridad está complementado con un sistema de radares y de cañones de agua (Ferrer, 2008). En definitiva, las fronteras de Ceuta y Melilla, si bien no se pueden considerar del todo impermeables - ninguna frontera del siglo XXI lo es-, se han protegido en extremo para evitar que continúe la migración ilegal masiva procedente de Marruecos.

8. Por ejemplo, desde 2012 se han ampliado las vallas fronterizas, se han segado las rutas de paso menos usuales como cañadas y arroyos, se han multiplicado los controles de vehículos y se ha instalado un nuevo sistema de vigilancia con 42 cámaras de última generación (Efe, 2013). 
Sin embargo, el esfuerzo español por contrarrestar el impacto de la migración ilegal no se centra solo en el control de fronteras, sino que tiene otra vertiente fundamental: la integración de la población migrante de Ceuta y Melilla. Las autoridades de las ciudades autónomas han puesto en marcha sendos programas de integración (CIDE, 2005), centrados especialmente en la inclusión de los jóvenes migrantes en las aulas y caracterizados por la introducción de posibilidades como la dar clases en árabe o amazigh de forma subvencionada o la de estudiar religión islámica en las escuelas. Dicha integración, dentro de sus posibles defectos, ha resultado razonablemente satisfactoria. La principal prueba de ello es que, a pesar de que el 90\% de la población migrante de Ceuta y Melilla es de religión musulmana y de procedencia marroquí, el irredentismo promarroquí no es mayoritario entre la población migrante. El principal partido musulmán de Ceuta, la Unión Demócrata Ceutí (3 diputados de los 25 de la Asamblea), no es nacionalista, y lo mismo sucede con el de Melilla, Coalición por Melilla (6 diputados de los 25 de la Asamblea).

Por otro lado, aunque el bloqueo marroquí en las negociaciones con la Comisión Europea sobre pesca es muy perjudicial para los intereses españoles, España ha hecho un gran esfuerzo por conseguir proporcionar a su flota pesquera nuevos caladeros en los que faenar, con el fin de diversificar la distribución geográfica de sus capturas y de reducir su dependencia de los caladeros tradicionales del Sáhara Occidental. Así, España, bajo el paraguas de la Comisión Europea, ha conseguido que se firmen acuerdos pesqueros con otros países africanos, y su flota opera ahora en países como Madagascar, Cabo Verde, Santo Tomé, Mozambique, Seychelles, Costa de Marfil o Kiribati, y tiene también acuerdos con Guinea-Bissau (Maté, 2012). Igualmente, ante las pérdidas económicas que ha supuesto el fin del acuerdo con Marruecos, España ha hecho de la pesca una prioridad de su diplomacia en Bruselas, lo que se aprecia en el incremento de la cuota pesquera española tras el acuerdo entre la UE y Noruega de 2013 (El País, 2013) y en la presión realizada por España para atraer el núcleo de las ayudas del Fondo Europeo Marítimo y de Pesca, tras una negociación de la que el ministro de Agricultura, Arias Cañete, salió diciendo que "España ha conseguido todos los objetivos que traía a la negociación" (La Vanguardia, 2012:1). De esta forma, aunque el bloqueo marroquí es una de las herramientas de presión que más perjudican a España, Madrid ha podido minimizar los daños ocasionados por dicho bloqueo.

Respecto a la intención marroquí de internacionalizar la controversia sobre la soberanía, España responde a Marruecos con sus mismas armas; es decir, reafirmando la españolidad de las plazas de soberanía y proyectando una imagen internacional de perfecta normalidad en el dominio español. Es por esta estrategia que, en los momentos de mayor tensión en las fronteras por la cuestión territorial, alguno de los más altos representantes de España se desplazan en viaje oficial a Ceuta y Melilla. Ello sucedió con la visita de los reyes de España a Ceuta y a Melilla en 2007, en un viaje que causó las protestas oficiales de Marruecos, así como un enfriamiento en las relaciones bilaterales (Bárbulo, 2007). Lo mismo ocurrió con la visitas de José Luis Rodríguez Zapatero a Ceuta y Melilla en 2006 y la de Mariano Rajoy a Melilla en 2010. Estas visitas oficiales son una útil herramienta para reafirmar la españolidad de estos territorios dentro de la 
normalidad institucional y del ámbito estrictamente diplomático, atraen casi la misma atención internacional que las reclamaciones hechas por Marruecos y sirven para catalizar el apoyo de la población local a España, con lo cual se contrarresta también la influencia ejercida por Rabat a través de organizaciones sociales de base con las que intenta atraer a partidarios de la anexión.

Por otro lado, España también se ha centrado mucho en paliar los efectos de la estrategia de presión marroquí relativa al tráfico de drogas. El medio principal para ello es el control de las fronteras, en relación con el incremento de la presencia española en las fronteras de Ceuta y de Melilla y con las mejoras de sus instalaciones. También se ha aumentado el dispositivo policial orientado al tráfico de drogas, en especial al proveniente de Marruecos, con lo que las detenciones de grupos y mafias marroquíes no cesan. Además, España ejerce presión en el seno de la Unión Europea para que esta exija más a Marruecos en materia de droga, y también intenta llevar a cabo labores de detección y de denuncia de forma independiente.

No obstante, España no puede permitirse llevar a cabo una estrategia limitada exclusivamente a contrarrestar las acciones marroquíes. Por el contrario, para defender sus intereses, debe asumir una actitud proactiva con la que consiga avanzar en sus intereses en Marruecos. Lo que España intenta conseguir con ello es, por una parte, ahondar en sus prioridades económicas relativas a Marruecos, y, por otra, lograr que, al tiempo que satisface sus intereses, Marruecos se vea tan inextricablemente ligado a España que le resulte contraproducente insistir en sus reclamaciones territoriales. Por un lado, España consigue esto gracias a la gran cantidad de dinero que gasta en cooperación al desarrollo en Marruecos, principal receptor de la Ayuda Oficial al Desarrollo (AOD) española en África y Oriente Próximo con más de la mitad del dinero total destinado a esas áreas (Castejón, 2004). La AOD española está claramente condicionada por motivos políticos, y es una herramienta utilizada por los Gobiernos españoles para intentar controlar a Marruecos, algo observable en los abruptos altibajos presentes en las cantidades anuales de dinero destinadas a Marruecos. Por ejemplo, la AOD se redujo en más de una tercera parte tras el conflicto de Perejil ${ }^{9}$. Además, la cooperación española está específicamente destinada a contener la inmigración marroquí - algo que se dice textualmente en el Plan Director de la AOD de 2001-2004, que define la cooperación española en Marruecos como una herramienta que incluye "soluciones al preocupante fenómeno de las migraciones" - , con lo que se puede observar que la estrategia de defensa española ante las presiones de Marruecos está muy entrelazada e interconectada (SECII, 2001:9).

9. El conflicto se inició cuando Marruecos ocupó el peñón de Perejil -deshabitado y reclamado por España - con una unidad de infantes de marina. Ante esto, España respondió con una importante operación militar con la que capturó a la unidad marroquí. El episodio, que se prolongó durante cinco días, estuvo a punto de desembocar en un conflicto mucho peor, y solo se resolvió gracias a la mediación estadounidense, aunque en él fueron fundamentales la firmeza y la rapidez de la actuación española. En definitiva, la crisis de Perejil constituye el ejemplo perfecto de hasta qué punto las reclamaciones territoriales marroquíes y las estrategias de presión de Rabat pueden dar lugar a un conflicto, y de hasta qué punto puede ser Marruecos una amenaza para España. 
Por otro lado, Madrid intenta satisfacer sus propios intereses económicos obteniendo del país vecino, a cambio de concesiones en otros ámbitos -como el de la cooperación al desarrollo-, ventajas para las empresas españolas en la región. Así, las relaciones económicas hispanomarroquíes están indefectiblemente marcadas por el Acuerdo de Asociación UE-Marruecos, y es innegable que, incluso en periodos de tensión entre ambos Estados, dichas relaciones son privilegiadas y muy estrechas, como muestra el aumento imparable del comercio bilateral desde 1995 (Muñoz, 2007). Marruecos es el principal destino, con diferencia, de las exportaciones españolas a África, ya que más del $40 \%$ de las exportaciones españolas a ese continente se dirigen a Marruecos. Además, España es el segundo país del que más importa Marruecos, solo por detrás de Francia, que además está perdiendo terreno frente a España en el mercado marroquí (Muñoz, 2007). Marruecos es, igualmente, el principal destino de la inversión española en África, ya que recibe casi el 80\% de esa inversión (Muñoz, 2007). Además, es importante señalar que la inversión española supone más del $26 \%$ de la inversión extranjera total en Marruecos, lo que favorece en gran medida la interdependencia económica entre España y Marruecos. Ese intento de hacer que la economía marroquí no pueda sostenerse sin la inversión española es uno de los principales caminos seguidos por España para intentar disminuir las tensiones diplomáticas que provocan las reclamaciones territoriales marroquíes.

Finalmente, la estrategia española incluye un poderoso elemento ante el que Marruecos poco puede oponer, aunque de difícil uso para España. Se trata del componente militar de la defensa española de las plazas de soberanía africanas, que tiene un carácter eminentemente disuasorio. La disuasión ante las amenazas externas es el fundamento esencial presente en la Directiva de Defensa Nacional 1/2012, en la que se dice que "es preciso mantener un nivel nacional de disuasión creíble y suficiente con objeto de evitar que los escenarios de riesgo en nuestro entorno geográfico se materialicen en amenazas", en clara referencia a Marruecos. El Libro Blanco de la Defensa dice también que, en caso de que la disuasión falle, la respuesta militar española debe seguir siendo efectiva, desde una perspectiva de atajar el conflicto en sus primeras fases, como sucedió en Perejil. Prueba de ello es que el contingente militar que España mantiene en el norte de África no ha sufrido ningún recorte ni en soldados ni en medios a pesar de las reducciones continuas en el presupuesto de Defensa, lo que da a entender la importancia que tiene para España conservar su capacidad de disuasión en la zona, capacidad que sigue siendo suficiente para defender Ceuta y Melilla en solitario ${ }^{10}$, según el ministro de Defensa, Pedro Morenés (Morenés, 2014).

10. España ha de hacer frente en solitario a ciertas particularidades en la defensa de Ceuta y Melilla, dado que no están incluidas en los acuerdos de defensa mutua de la OTAN. Este hecho, combinado con la tibia respuesta de los aliados europeos durante la crisis de Perejil, obliga a España a mantener un notable dispositivo propio en la zona, ante la seguridad de que no tendrá ayuda militar exterior en caso de conflicto. 


\section{CONCLUSIONES}

España y Marruecos, para bien o para mal, son dos países condenados a entenderse. Su proximidad geográfica y su interdependencia económica, junto con los lazos humanos que los unen, hacen que las relaciones bilaterales entre ellos sean relativamente cordiales y amigables. Sin embargo, en el contexto de las relaciones hispano-marroquíes hay otros elementos que introducen periódicamente dinámicas mucho más cercanas a la tensión y al conflicto que a la buena vecindad. El principal de esos elementos es sin duda el de las reclamaciones territoriales de Marruecos. El propósito de este trabajo era el de analizar hasta qué punto esos elementos de conflictividad presentes en las relaciones hispano-marroquíes pueden llegar a suponer una amenaza real para España. Aunque hay quienes niegan que exista siquiera tal amenaza y que tachen de nacionalismo, etnocentrismo y xenofobia cualquier mención al respecto, parece evidente que el mero hecho de que Marruecos no reconozca las actuales fronteras españolas ya supone una amenaza para la seguridad nacional de España. La opinión sobre la existencia de una amenaza real es compartida por el ministerio de Defensa español, que afirma que "el riesgo sobre Ceuta y Melilla no solo es permanente, sino que además, si no se gestiona adecuadamente desde el plano político, es susceptible de degenerar en un conflicto bélico" (Ceseden, 2011:24).

Una vez aclarado el hecho de que existe, en efecto, una amenaza, y de que esta es una constante en la seguridad nacional española la conclusión de este trabajo es que dicha amenaza es muy seria. Al margen del terrorismo global, la principal amenaza de carácter convencional y estatal para España proviene de Marruecos. El uso ventajista y cíclico, aunque no periódico, de la cuestión territorial es lo que más inseguridad aporta a las relaciones bilaterales, porque España nunca sabe cuándo van a reproducirse de nuevo brotes nacionalistas en el contexto marroquí.

Además, las estrategias marroquíes son dañinas para España en muchos otros frentes -como el de la inmigración ilegal, el de la droga o el económico, como es el caso del bloqueo de los acuerdos pesqueros-, lo que a su vez aumenta la amenaza marroquí para la seguridad española. España ha intentado contrarrestar esas estrategias de presión, pero, aunque sin duda han contribuido a reducir su impacto, no han podido paliar del todo ni el daño ni el riesgo que entrañan para Madrid las tácticas marroquíes. Finalmente, en esta disertación se ha demostrado que, lejos de ser una cuestión meramente académica o teórica, la amenaza marroquí es tan palpable que, en determinadas circunstancias, puede desembocar incluso en un conflicto bélico, como estuvo a punto de ocurrir en 2002 con el caso de Perejil.

En definitiva, si el propósito de este análisis era determinar el grado de amenaza representado por Marruecos, la conclusión es que, indudablemente, la amenaza este y es bastante significativa. A día de hoy es prácticamente imposible que la situación de Ceuta, Melilla y los demás territorios reclamados varíe, ya que la posición de España en ellos es fuerte, pero la amenaza para España se extiende por otras vías, como aquí se ha comprobado. No es improbable, por ejemplo, que se repita una crisis como la de Perejil, ni que Marruecos intente otras tácticas, 
aunque igual de directas, para cumplir sus ambiciones territoriales. En resumen, los datos analizados muestran que, efectivamente, existe una amenaza real para España representada por Marruecos, una amenaza que es cambiante e inestable, que, aunque siempre se centra en el tema territorial, no se circunscribe únicamente a él, y que, en definitiva, constituye una constante en la seguridad nacional española.

\section{REFERENCIAS}

- Amnistía Internacional (2006), España: frontera sur, accedido desde: http://www. es.amnesty.org/temas/refugio-e-inmigracion/espana-frontera-sur/

- Ballesteros, M. (2013), "El valor geoestratégico de las Islas Canarias", Instituto Español de Estudios Estratégicos, Documento Análisis 09/2013.

- Bárbulo, T. (2007), “El Rey destaca que su visita a Ceuta cumple un compromiso pendiente", accedido desde: http://elpais.com/diario/2007/11/06/espana/1194303603_850215.html

- $\quad$ Bartumeus, L. (2004), "La relevancia del Estrecho para el planeamiento estratégico español", Real Instituto Elcano, accedido desde: http://www.realinstitutoelcano.org/ wps/portal/rielcano/contenido?WCM_GLOBAL_CONTEXT=/elcano/elcano_es/zonas_es/ defensa $+y+$ seguridad/ari+181-2004

- Calvo, E. (2011), "Marruecos recuerda que recuperar Ceuta y Melilla es un objetivo nacional", El Mundo, accedido desde: http://www.elmundo.es/elmundo/2011/03/28/ espana/1301328502.html

- Castejón, A. (2004), “La Cooperación española para el Desarrollo en Marruecos, en López, B. y Berriane, M. (directores), Atlas de la inmigración marroquí en España 2004. Madrid, Universidad Autónoma de Madrid.

- Ceseden (Centro Superior de Estudios de la Defensa Nacional), (2011), Los intereses geopolíticos de España: panorama de riesgos y amenazas, Madrid, Ministerio de Defensa, accedido desde: http://www.defensa.gob.es/ceseden/Galerias/destacados/publicaciones/ docSegyDef/ficheros/043_LOS_INTERESES_GEOPOLITICOS_DE_ESPANA_PANORAMA_DE_

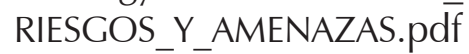

- CIDE (Centro de Investigación y Documentación Educativa), "La atención al alumnado inmigrante en el sistema educativo en España", Colección Investigación, n.o 168, Madrid, Ministerio de Educación.

- Del Miño, P. (2005), Las relaciones entre España y Marruecos, Madrid, Catarata. 
- Echeverría, C. (2002), "Relaciones hispano-marroquís: una compleja agenda", Real Instituto Elcano, accedido desde: http://www.realinstitutoelcano.org/wps/ portal/rielcano/contenido?WCM_GLOBAL_CONTEXT=/elcano/elcano_es/zonas_es/ mediterraneo $+y+$ mundo + arabe/dt4-2002

- Efe, (2013), "Interior refuerza la frontera de Melilla con 42 cámaras nuevas", ABC, accedido desde: $\quad$ http://www.abc.es/espana/20130110/abci-frontera-melilla-201301101339. html

- El País (2013), La flota española tendrá mejores cuotas de pesca tras el acuerdo UE-Noruega, accedido desde: http://economia.elpais.com/economia/2013/01/18/ actualidad/1358529975_851923.html

- Eurostat (2012), Fishery statistics, accedido desde: http://epp.eurostat.ec.europa.eu/ statistics_explained/index.php/Fishery_statistics

- Ferrer, X. (2008), “Acrobacias fronterizas en Ceuta y Melilla. Explorando la gestión de los perímetros terrestres de la Unión Europea en el continente africano", Documents d'Anàlisi Geogràfica n.․ 51, Barcelona, Universitat Autònoma de Barcelona.

- García Figueras, T. (1939), Marruecos: la acción española en el norte de África, Madrid, Ediciones Fe.

- GEVIC (Gran Enciclopedia Virtual de las Islas Canarias), (2012), La pesca en Canarias, accedido desde: http://www.gevic.net/info/contenidos/mostrar_contenidos.php?idcomarca=-1\&id con $=850 \&$ idcap $=208 \&$ idcat $=21$

- González, E. (2013), "Marruecos debate legalizar el cannabis", El Confidencial, accedido desde: http://www.elconfidencial.com/mundo/2013-11-20/marruecos-debate-legalizarel-cannabis_56465/

- Gottmann, J. (1973), The significance of territory, Charlottesville, Estados Unidos, University of Virginia Press.

- Gutiérrez, M. (2010), "Marruecos vuelve a la carga en su reivindicación de Ceuta y Melilla", La Razón, accedido desde: http://www.larazon.es/detalle_hemeroteca/noticias/ LA_RAZON_316289/6177-marruecos-vuelve-a-la-carga-en-su-reivindicacion-de-ceuta-ymelilla\#.UV'GAIDcTTjY

- Holgado, M. y Ostos, M. (2012), "Los acuerdos de pesca marítima entre España y Marruecos: evolución histórica y perspectivas", Estudios agrosociales y pesqueros, N.․․ 194. 
- ICE (Instituto Canario de Estadística), (2012), Turistas según lugares de residencia por islas de destino principal y periodos, accedido desde: http://www.gobiernodecanarias.org/ istac/jaxi-web/tabla.do

- INE (Instituto Nacional de Estadística), (2012), Consumo de energía primaria por tipo de energía, periodo e indicador, accedido desde: http://www.ine.es/jaxi/tabla.do

- INE (Instituto Nacional de Estadística), (2012), Entrada de turistas por país de residencia, indicador y periodo, accedido desde: http://www.ine.es/jaxi/tabla.do

- INE (Instituto Nacional de Estadística), (2012), Población, superficie y densidad por municipios, accedido desde: http://www.ine.es/jaxi/tabla.do

- La Vanguardia (2012), España logra sus objetivos en el nuevo acuerdo de la UE sobre pesca, accedido desde: http://www.lavanguardia.com/economia/20121024/54353411959/ espana-acuerdo-ue-pesca.html

- Lobina, M. (2013), Los intereses pesqueros de España y Marruecos encallan en Europa, accedido desde: http://latitud194.com/?analisis=los-intereses-pesqueros-de-espana-ymarruecos-encallan-en-europa

- Marquina, Antonio, El problema de Ceuta y Melilla en la estrategia internacional española, 2008, http://www.cuentayrazon.org/revista/pdf/027/Num027_008.pdf

- Maté, V. (2012), "Barcos sin caladeros", EL PAíS, accedido desde: http://economia.elpais. com/economia/2012/12/21/actualidad/1356105062_329615.html

- Montero, H. (2012), "La batalla por el petróleo canario", La Razón, http://www.larazon. es/detalle_hemeroteca/noticias/LA_RAZON_432338/2450-la-batalla-por-el-petroleocanario\#.ÜVA8YTcTTjY

- Morenés, P. (2014), "Entrevista a Pedro Morenés", One Magazine n.o 1, Madrid, Grupo Atenea.

- Munáiz, C. (2009), “La BBCcomparalas vallas deCeutay Melilla con elMurodeBerlín”, Periodista digital, accedido desde: http://www.periodistadigital.com/periodismo/internet/2009/11/05/labbc-compara-las-vallas-de-ceuta-y-melilla-con-el-muro-de-berlin.shtml

- Muñoz, S. (2007), "Las relaciones económicas entre España y Marruecos: dos socios privilegiados", Boletín económico de la revista ICE (Información Económica Española) n.. 2918, accedido desde: http://www.revistasice.com/cachepdf/BICE_2918_23-39_ CCD03DF6DFD75A03C219610E374965D7.pdf 
- Navarro del Rey, M. (2001). El español como segunda lengua en Ceuta, Granada, Universidad de Granada.

- Oficina de las Naciones Unidas contra la Droga y el Crimen (2012), Informe mundial sobre las drogas, accedido desde: http://www.unodc.org/documents/data-and-analysis/ WDR2012/WDR_2012_Spanish_web.pdf.

- Organización de Naciones Unidas (2012), Índice de Desarrollo Humano - Clasificación de 2011, accedido desde: http://hdr.undp.org/es/estadisticas/.

- Organización de Naciones Unidas (2013), Las Naciones Unidas y la descolonización: territorios no autónomos, accedido desde: http://www.un.org/es/decolonization/ nonselfgovterritories.shtml.

- Pérez, A. (2013), "La seguridad en las relaciones hispano-marroquíes", Atenea, accedido desde: http://www.ateneadigital.es/RevistaAtenea/REVISTA/articulos/ GestionNoticias_1608_ESP.asp.

- Planet, A. (2000), Ceuta y las migraciones marroquíes, Madrid, Universidad Autónoma de Madrid, accedido desde: http://www.uam.es/otroscentros/TEIM/Observainmigra/Atlas\%20 1996/04\%20cap\%204/Ceuta.pdf.

- Puertos de Las Palmas (2013), Tráfico marítimo del último año, accedido desde: http:// www.palmasport.es/00000/paginas/html/default.htm.

- Ruiz,C.(2003), "Lasrelacioneshispano-marroquíes:ivvueltaaempezar?”, ReallnstitutoElcano, accedido desde: http://www.realinstitutoelcano.org/wps/portal/rielcano/contenido?WCM_ GLOBAL_CONTEXT=/elcano/elcano_es/zonas_es/mediterraneo $+y+$ mundo + arabe/ ari+38-2003.

- San Martín, N. (2008), "España, coladero de la droga en Europa", Fundación Dialnet n.․ 953, Logroño, Universidad de la Rioja.

- SECII (Secretaría de Estado para la Cooperación Internacional y para Iberoamérica), (2001), Plan Director de la cooperación española 2001-2004 (p. 10), Madrid, Ministerio de Asuntos Exteriores.

- Sueiro, S. (2003), "La política mediterránea", en Portero et al., La política exterior de España en el siglo XX, Madrid, Marcial Pons, 185-202.

- Téllez, J. (2012), "Yahya Yahya, patriota y maltratador", Público, accedido desde: http:// www.publico.es/espana/441554/yahya-yahya-patriota-y-maltratador. 